\title{
Modified Hammerhead Ribozymes as Potential Therapeutics
}

\author{
Joachim W. Engels*, Michaela Scherr, Arnold Ganser ${ }^{1}$, Manuel Grez $^{2}$ \\ and Valentin Wittmann \\ Institut für Organische Chemie, Johann Wolfgang Goethe-Universität \\ Marie-Curie-Str. 11, D-60439 Frankfurt amMain, Germany \\ ${ }^{1}$ Medizinische Hochschule Hannover, 30625 Hannover, Germany \\ ${ }^{2}$ Georg-Speyer-Haus, 60596 Frankfurt am Main, Germany
}

\begin{abstract}
Hammerhead ribozymes were modified in the 2'-position by flouro-, amino-, deoxy-, O-methyl- and methoxyethoxy-groups to stabilize against degradations. They were tested for their ability to cut specifically oncogenic N-ras RNA in vitro. Exogenous delivery by lipofection as well as viral vector mediated transfection showed comparable results in reducing $\mathrm{N}$-ras mRNA.
\end{abstract}

INTRODUCTION: Synthetic oligonucleotides show great promise as therapeutic entities, be it by acting as antisense, ribozyme or triplex constructs. The latter are based on RNA-structures derived from nature which have to be suitably modified in order to be applicable in cells or living organism.

One of the best understood ribozymes, the hammerhead ribozyme ${ }^{1}$, originates from plant viruses. For efficient cleavage a consensus sequence is required consisting of a NUH base triplett at the juncture of three base paired stems including 11 consensus nucleotides (FIG. 1). Whereas originally the reaction takes place in cis under single turnover conditions it has been demonstrated that it also behaves like a true enzyme cleaving in trans. In the presence of $\mathrm{Mg}^{2+}$ transesterification leaves a $5^{\prime}$-hydroxyl on one side and a $2^{\prime}-3^{\prime}$-cyclic phosphate on the other side ${ }^{2}$. Based on a good number of analog structure

\footnotetext{
' correspondence to J.W. Engels, Phone: +496979829150 ; Fax: +496979829148

e-mail: engels@ewsl.org.chemie.uni-frankfurt.de
} 


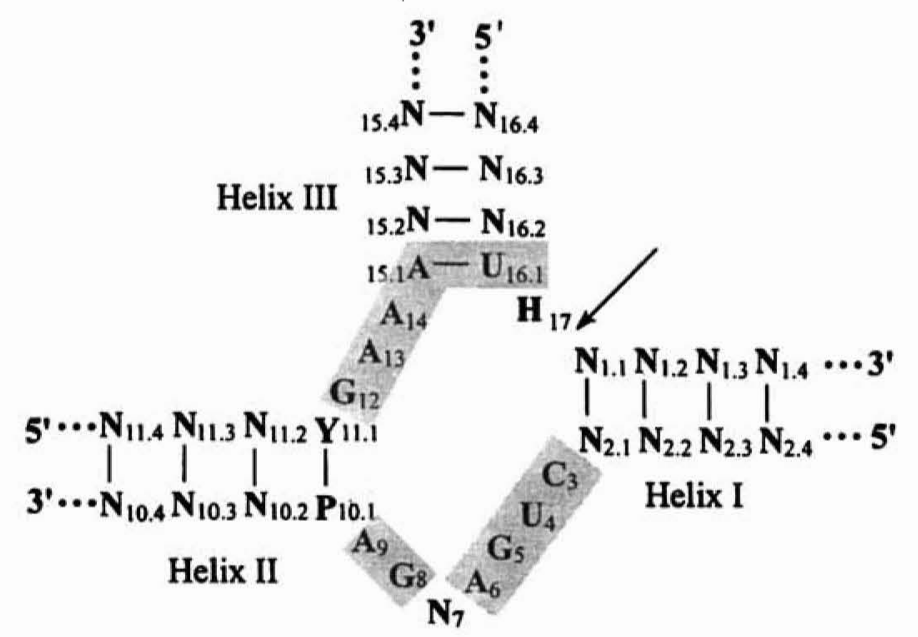

FIG. 1. Consensus sequence of the hammerhead ribozyme. Numbering system according to Hertel et al. ${ }^{3}$ Conserved nucleotides are shaded. $\mathrm{N}=$ any nucleotide; $\mathrm{P}=\mathrm{A}$ or $\mathrm{G} ; \mathrm{Y}=$ $\mathrm{U}$ or $\mathrm{C} ; \mathrm{H}=\mathrm{A}, \mathrm{C}$ or $\mathrm{U}$.

studies the design of therapeutic ribozymes is possible now. Important prerequisites which have to be considered in the design are the target delivery, the stability in cells and the efficient catalysis in destroying the target mRNA.

For target delivery we choose lipofection as one method (exogenous application) and viral vector-mediated delivery (endogenous application) as the other alternative. Since unmodified RNA is unstable in sera chemical modification has to be performed for exogenous delivery. Initially we relied on the studies of Eckstein et al. ${ }^{4}$ in choosing sugar modifications as $2^{\prime}$-fluoro and $2^{\prime}$-amino- substituents. Furthermore 2'-deoxy-, 2'-Omethyl and $2^{\prime}$-methoxyethoxy substituents were tested. For all these modifications efficient catalysis was determined. The introduction of phosphothioates at the ends led to a nearly complete stability.

The growth and differentiation of cells depends on a variety of parameters one of which is a complex signal transduction. The proteins coded by the three ras-genes (Ha-ras, Nras, Ki-ras) are involved in the cell signal transduction and are members of the super gene family of small GTP/GDP binding proteins ${ }^{5}$. Ras mutations have been found in tumours $^{6}$, neuroblastoma, acute myeoloblastic leukaemia (AML), chronic myelogenous 
leukaemia (CML) and multiple myeloma ${ }^{7}$. Studies of ras-oncogenes in tumours have revealed several point mutations in codon $12,13,59$ or 61 which cause structural changes in the GTP binding site and reduce GTPase activity. Mutant ras proteins, having a reduced ability to hydrolyze GTP, remain in the active state and thus stimulate cell growth or differentiation autonomously. The inhibition of this incorrect signal transduction by ribozymes may lead to an efficient anti-cancer therapy.

RESULT AND DISCUSSION: In the present study we report the synthesis and catalytic properties of several hammerhead ribozymes targeted against mutant N-ras transcripts. As outlined above essential point mutations in codon 12 and 13 of the mRNA are responsible for autonomous growth. On the DNA-level (FIG. 2) these mutations create the consensus motif (NUH) for hammerhead recognition.

Thus, we constructed two ribozymes targeted against these regions named MRE763C and MRE764U. GC transversion at position 763 generates a GUC triplet which is targeted by the ribozyme MRE763C (FIG. 3A). Ribozyme MRE764U is targeted against a second GT transversion at position 764 generating a GUU triplet (FIG. 3B).

The ribozymes MRE763C and MRE764U are highly specific as they only cleave oncogenic $\mathrm{N}$-ras sequences containing a point mutation in codon 13 at position 763 or 764. Incubation of MRE763C with a 849 nucleotide long mutant $\mathrm{N}$-ras transcript resulted in the expected cleavage products of 534 and 315 bases (FIG 4A). The same result was obtained for ribozyme MRE764U (data not shown). In contrast, incubation of MRE763C with transcripts containing the wild-type $\mathrm{N}$-ras sequences did not result in any detectable substrate (FIG 4B).

Since the final goal of our experiments was to demonstrate the efficiency of these ribozymes in cell culture, pyrimidine ribonucleotides containing 2'-hydroxyl substitutions were used for increasing the stability of the oligoribonucleotides against degradation by RNases. The modifications tested were 2'-deoxy, 2'-O-methyl-, 2'-Omethoxyethoxy-, $2^{\prime}$-fluoro-deoxypyrimidine and $2^{\circ}$-amino-deoxyuridine (FIG. 5).

The modified ribozymes were incubated in cell culture media at $37^{\circ} \mathrm{C}$ for up to $120 \mathrm{~h}$ and assayed for cleavage as described ${ }^{8}$. While the unmodified ribozyme was degradated within half a minute, the introduction of three phosphorothioate linkages at the 3 '-end of 


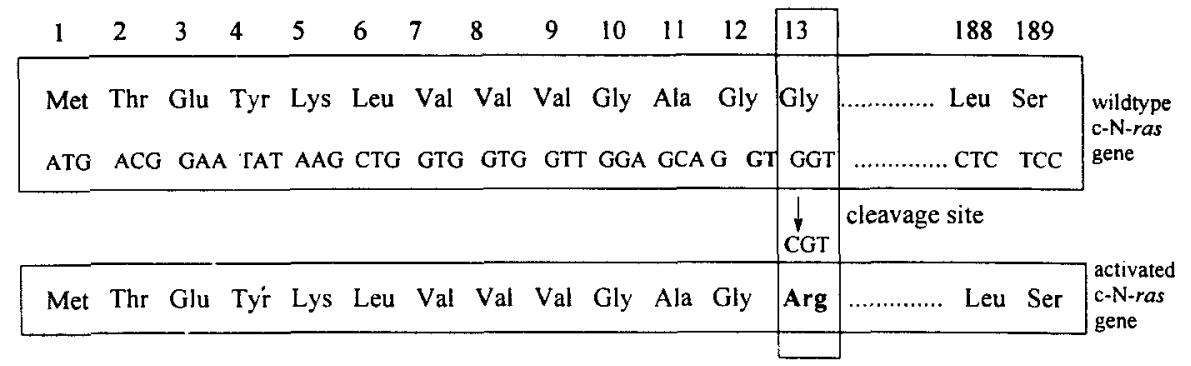

FIG. 2. Point mutation in codon 13 GGT (Gly) $\rightarrow$ CGT (Arg) leads to an activated N-ras oncogene and to a potential ribozyme cleavage site GUG $\rightarrow$ GUC.

A

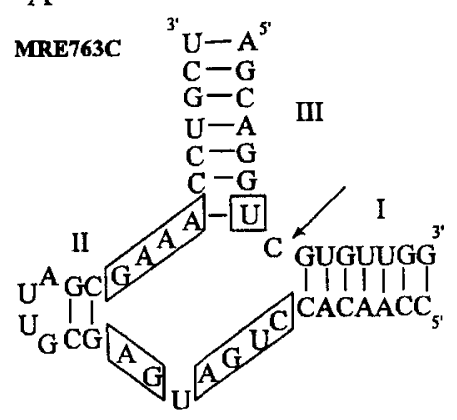

$\mathrm{B}$

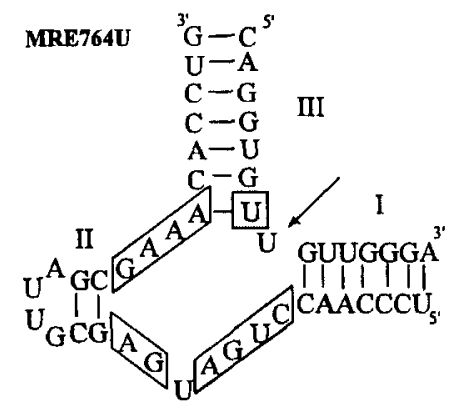

FIG 3. Schematic representation of the chemically synthesized hammerhead ribozymes directed against oncogenic N-ras mRNA. The cleavage site is indicated by an arrow and the point mutation is shaded.

the ribozyme and one at the 5'-end increased the half-life of ribozymes to 2-3 minutes. Other modifications (e.g. 2'-fluoro-2'-deoxyuridine) led to a further increase in stability (TAB. 1). Finally, complete substitution of all pyrimidine nucleotides (e.g. 2'-fluoro-2'deoxycytidine or $2^{\prime}$-methoxy-ethoxy) prevented ribozyme degradation for up to $80 \mathrm{~h}$. Most of the modified ribozymes were still capable of cleaving the oncogenic N-ras transcripts. Introduction of 2'-fluoro-2'-deoxypyrimidine into ribozymes led to a 2-or 3fold decrease in catalytic activity compared to the unmodified ones which did not depend on the presence or absence of terminal phosphorothioates (TAB. 2). In contrast, substitution of the 2'-hydroxyl group by 2'-O-methyl-2'-deoxyuridine/cytidine or 2'- 
A

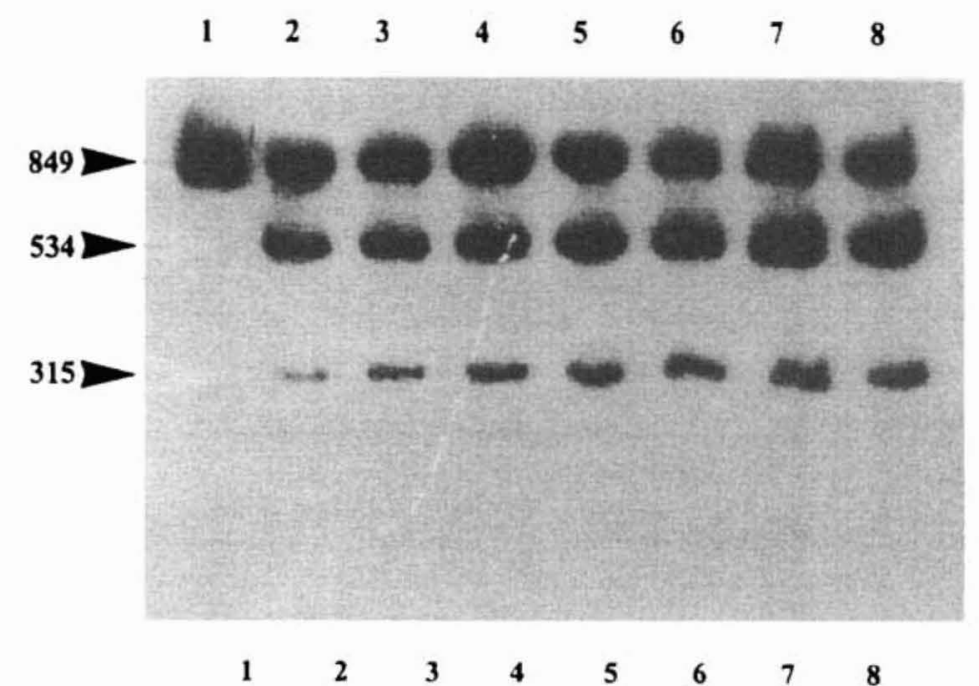

B

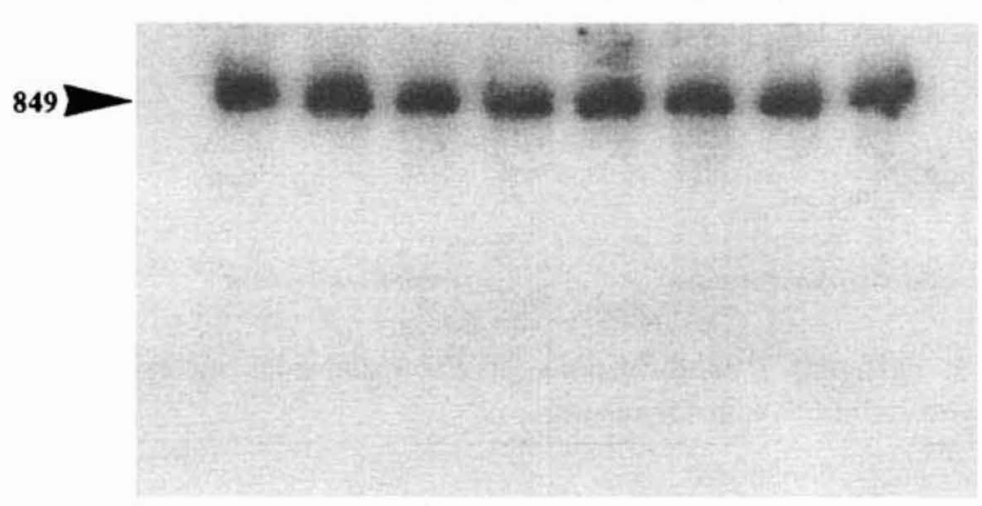

FIG 4. Kinetics of ribozyme cleavage with full-length N-ras transcripts. MRE763C was incubated with a 849-nucleotide-long oncogenic (A) or wildtype (B) N-ras transcript for $1 \mathrm{~h}$ at $37^{\circ} \mathrm{C}$. The substrate concentrations used were $2 \mathrm{nM}$ and ribozyme concentrations were $20,40,50,60,80,100$, or $120 \mathrm{nM}$ (lane 2-8) in the presence of $10 \mathrm{mM} \mathrm{MgCl}_{2}$. Lane 1 shows the untreated substrate.

methoxyethoxy-2'-deoxyuridine/cytidine led to a complete loss of activity. The best results were obtained by introducing 2'-amino-2'-deoxy uridine in the $\mathrm{U}_{4}, \mathrm{U}_{7}$-positions in the 2'-flouro or 2'-methoxyethoxy modified ribozyme ${ }^{4,8,9}$. Recently by heteronuclear NMR we could show that 2 -fluoro groups in RNA not only change the thermodynamic ratio of the $2^{\prime}-3^{\prime}$-endo sugar conformation but also influence their kinetic exchange rate by slowing down the pseudorotation phase $\mathrm{e}^{10}$. According to these results, modified 


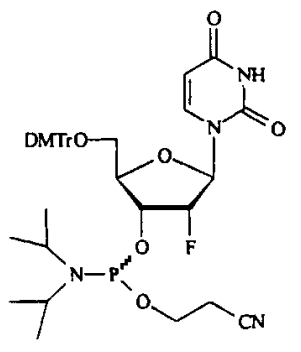

2'-fluoro-2'-deoxyuridine

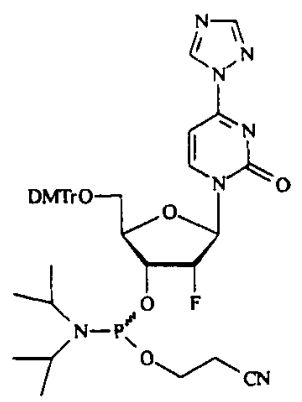

2'-fluoro-2'-deoxy-N-1,2,4-triazolouridine

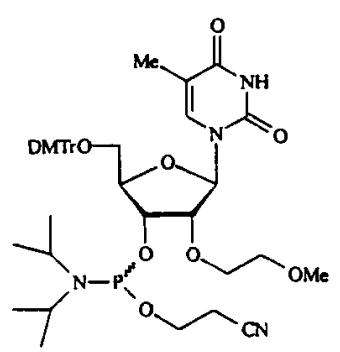

2'-methoxyethoxythymidine

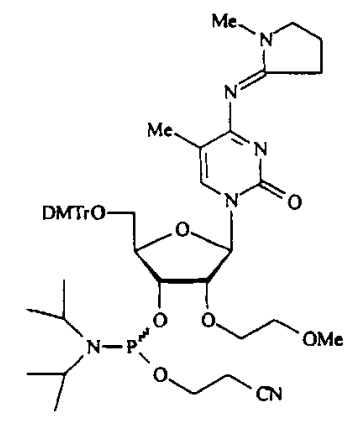

2'-methoxyethoxy-5-methylcytidine

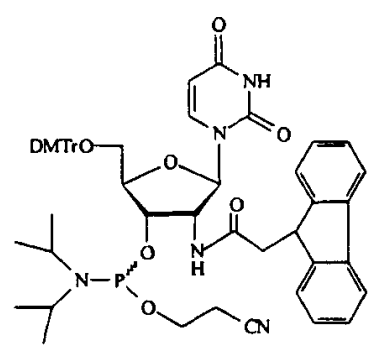

2'-amino-2'-deoxyuridine

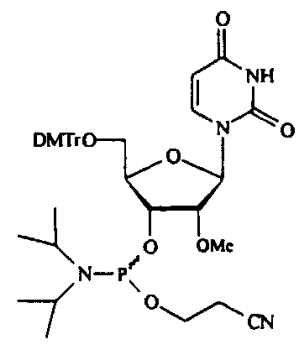

2'-O-methyl-2'-deoxyuridin

FIG. 5. Different 2'-modifications of ribonucleosides incorporated into a ribozyme leading to stability against nucleases.

ribozymes containing 2'-fluoro-2'-deoxycytidine and 2'-fluoro-2'-deoxyuridine with or without phosphorothioate groups were used for the studies in cell culture.

To examine the cleavage properties of the modified ribozymes ex vivo, a N-ras/luciferase fusion minigene was constructed. A 452 bp N-ras DNA fragment, containing 50 bp 5'untranslated sequences, the $\mathrm{N}$-ras translation initiation codon and sequences coding for the first 134 amino acids of wildtype or mutant N-ras, was fused in frame with the firefly luciferase gene changing the AUG translation initiation codon of the luciferase gene to AUA. In this construct the expression of the luciferase gene is under the control of the $\mathrm{N}$ ras gene, thus, cleavage of $\mathrm{N}$-ras sequences by ribozymes can be monitored by the reduction in luciferase activity. 
TABLE 1. Stability of modified ribozymes in cell culture media.

\begin{tabular}{|c|c|}
\hline Ribozyme & Cell supernatants (half-life-times) \\
\hline Unmodified & $0.5 \mathrm{~min}$ \\
\hline $\mathbf{S}$ & $3.0 \mathrm{~min}$ \\
\hline $\mathbf{S}, \mathbf{F U}$ & $10.0 \mathrm{~min}$ \\
\hline FU, FC & $50 \mathrm{~h}$ \\
\hline $\mathrm{FU}, \mathrm{FC}, \mathrm{U}_{4} \mathrm{U}_{7}-\mathrm{NH}_{2}$ & $50 \mathrm{~h}$ \\
\hline $\mathrm{S}, \mathrm{FU}, \mathrm{OMeC}$ & $80 \mathrm{~h}$ \\
\hline S, OMeU, OMeC & $80 \mathrm{~h}$ \\
\hline $\mathbf{S}, \mathbf{d U}, \mathbf{d C}$ & $80 \mathrm{~h}$ \\
\hline $\mathbf{S}, \mathbf{F U}, \mathbf{F C}$ & $80 \mathrm{~h}$ \\
\hline EtOMeU, EtOMeC, $\mathrm{U}_{4} \mathrm{U}_{7}-\mathrm{OH}$ & $30.0 \mathrm{~min}$ \\
\hline EtOMeU, EtOMeC, $\mathrm{U}_{4} \mathrm{U}_{7}-\mathrm{NH}_{2}$ & $80 \mathrm{~h}$ \\
\hline EtOMeU, EtOMeC, $\mathrm{U}_{4} \mathrm{U}_{7}-\mathbf{F}$ & $80 \mathrm{~h}$ \\
\hline EtOMeU, EtOMeC & $80 \mathrm{~h}$ \\
\hline S, EtOMeU, EtOMeC, $\mathrm{U}_{4} \mathrm{U}_{7}-\mathrm{NH}_{2}$ & $80 \mathrm{~h}$ \\
\hline S, EtOMeU, EtOMeC, $\mathrm{U}_{4} \mathrm{U}_{7}-\mathrm{F}$ & $80 \mathrm{~h}$ \\
\hline
\end{tabular}

TABLE 2. Catalytic efficiencies of several modified hammerhead ribozymes with in vitro transcribed N-ras RNA (nd, not detectable).

\begin{tabular}{|c|c|c|c|c|c|}
\hline Ribozyme & Modification & $\begin{array}{c}\mathbf{k}_{\text {react }} \\
{\left[10^{-6} \mathrm{~s}^{-1}\right]}\end{array}$ & $\begin{array}{c}\mathbf{K}_{\mathbf{M}} \\
{[\mathrm{nM}} \\
]\end{array}$ & $\begin{array}{c}\mathbf{k}_{\text {react }} / \mathbf{K}_{\mathbf{M}} \\
{\left[\mathrm{s}^{-1} \mathrm{M}^{-1}\right]}\end{array}$ & $\underset{\text { (relative) }}{\mathbf{k}_{\text {react }} / \mathbf{K}_{\mathbf{M}}}$ \\
\hline \multirow[t]{2}{*}{ MRE764U } & & 137 & 113 & 1212 & 1 \\
\hline & FU, FC & 62 & 120 & 516 & 0.40 \\
\hline \multirow[t]{11}{*}{ MRE763C } & & 266 & 71 & 3752 & 1 \\
\hline & FU, FC & 50 & 39 & 1266 & 0.340 \\
\hline & FU, FC, $U_{4} U_{7}-N_{2}$ & 173 & 71 & 2437 & 0.650 \\
\hline & EtOMeU, EtOMeC, $\mathrm{U}_{4} \mathrm{U}_{7}-\mathrm{OH}$ & 147 & 51 & 2882 & 0.770 \\
\hline & EtOMeU, EtOMeC, $\mathrm{U}_{4} \mathrm{U}_{7}-\mathrm{NH}_{2}$ & 173 & 73 & 2370 & 0.630 \\
\hline & EtOMeU, EtOMeC, $\mathrm{U}_{4} \mathrm{U}_{7}-\mathrm{F}$ & 39 & 135 & 288 & 0.077 \\
\hline & EtOMeU, EtOMeC & nd & nd & nd & nd \\
\hline & OMeU, OMeC & nd & nd & nd & nd \\
\hline & $\mathbf{S}, \mathbf{F U}, \mathbf{F C}$ & 51 & $\overline{44}$ & 1159 & 0.300 \\
\hline & S, EtOMeU, EtOMeC, $U_{4} U_{7}-\mathbf{F}$ & nd & nd & nd & nd \\
\hline & S, EtOMeU, EtOMeC, $\mathrm{U}_{4} \mathrm{U}_{7}-\mathrm{NH}_{2}$ & 27 & 190 & 142 & 0.038 \\
\hline
\end{tabular}


HeLa cells were transfected with plasmids containing either wild-type or mutant $\mathrm{N}$ ras/luciferase fusion gene under the transcriptional control of a CMV promoter/enhancer element and neomycin selection. The HeLa cell clones C\#3 (GGT to CGT mutation at position 763), T\#4 (GGT to GTT transversion at position 764) and W\#2 (wildtype N-ras sequence) showed the highest luciferase activity and were chosen for all subsequent experiments. These clones were transiently transfected with the ribozymes MRE763C and MRE764U using LipofectAMINE ${ }^{\mathrm{TM}}$. As a control for unspecific cleavage, a ribozyme containing an active catalytic site but no homology to the target $\mathrm{N}$-ras sequence was used (nonsense ribozyme). It was chosen for $100 \%$ luciferase acticvity (reference). Similarly, catalytically inactive ribozymes containing an adenosine residue instead of guanosine at position 5 (iMRE763C and iMRE764U) were used to estimate the reduction in luciferase activity caused solely by the hybridization of the ribozymes to the target sequences (antisense effect).

The ribozyme MRE763C, targeted against the mutation at position 763 of the $\mathrm{N}$ ras/luciferase mRNA, was most effective in inhibiting luciferase gene expression. An inhibition of up to $60 \%$ was observed at a ribozyme concentration of $10 \mu \mathrm{M}$ (FIG. 6). These results were confirmed by the studies with ribozyme MRE764U. A minor decrease in luciferase activity (20\%) was seen with the inactive ribozymes iMRF764U and iMRE763C, which can be explained by an antisense effect.

When HeLa cell clone W\#2, which expresses wild-type N-ras sequence, was treated with MRE763C a $20 \%$ reduction in luciferase was observed. This value is within the range of the luciferase activity obtained from HeLa cells treated with the inactive form of the ribozyme (iMRE763C) and thus is probably due to an antisense effect of ribozyme MRE763C on the wild-type N-ras/luciferase mRNA.

Although the reduction in luciferase activity suggests that the ribozymes MRE764U and MRE763C cleave the fusion mRNA efficiently, a quantitative assessment of RNA molecules cleaved by the ribozymes is not possible by this assay. For that, a semiquantitative RT-PCR reaction was established. Total RNA was isolated from clone C\#3 by the guanidine-isothiocyanate method. Great care was taken ${ }^{\text {Il }}$ to estimate the degree of $\mathrm{N}$-ras/luciferase mRNA cleavage during the extraction protocol by using an internal 


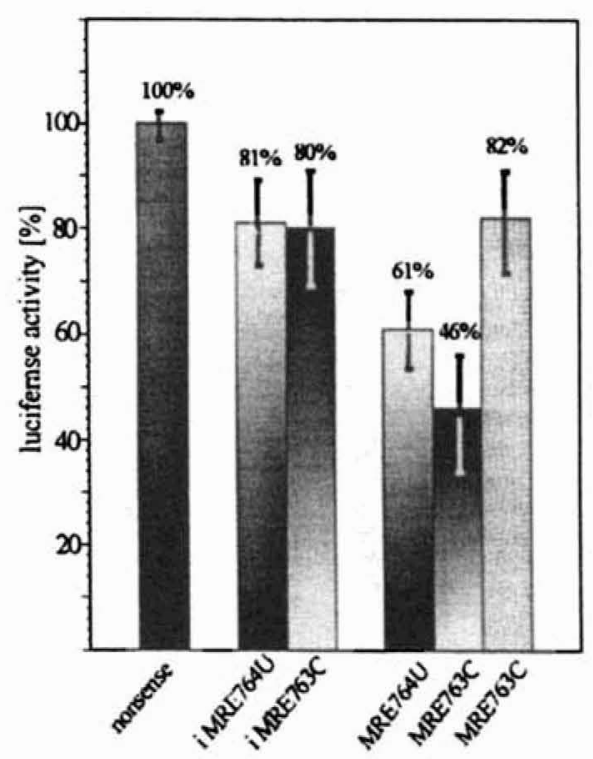

FIGURE 6. Inhibition of luciferase activity in HeLa cells expressing oncogenic or wildtype $\mathrm{N}$-ras/luciferase transcript by ribozymes.

control. For this, a 50 bp oligonucleotide was cloned within the ras sequences in the expression vector pcDNA3-LUCFUC and utilized as control in the RT-PCR.

Total RNA obtained from the HeLa cell clone $\mathrm{C \# 3}$ was mixed with the internal standard RNA at a molar ratio of approximately 1 . Upon reverse transcription, followed by a DNA-PCR the internal standard control should generate a 450 bp long PCR product, while amplification of a segment of the N-ras/luciferase fusion mRNA should generate a 394 bp DNA fragment.

The RT-PCR done on RNA obtained from clone C\#3 treated with the nonsense ribozyme gave the expected product of 394 bp (FIG. 7, lane 5). Based on band intensities (FIG. 7, lane 4), no significant reduction was observed suggesting that treatment of the cells with a nonsense ribozyme does not reduce the amount of N-ras/luciferase transcripts. In addition, cleavage of the internal control was not observed. In contrast, treatment of cells with the active ribozyme MRE763C caused a significant reduction in N-ras transcripts. For clinical application of ribozymes, high catalytic efficiency, stability and good availability has to be achieved. Rapid degradation of oligoribonucleotides in living cells 


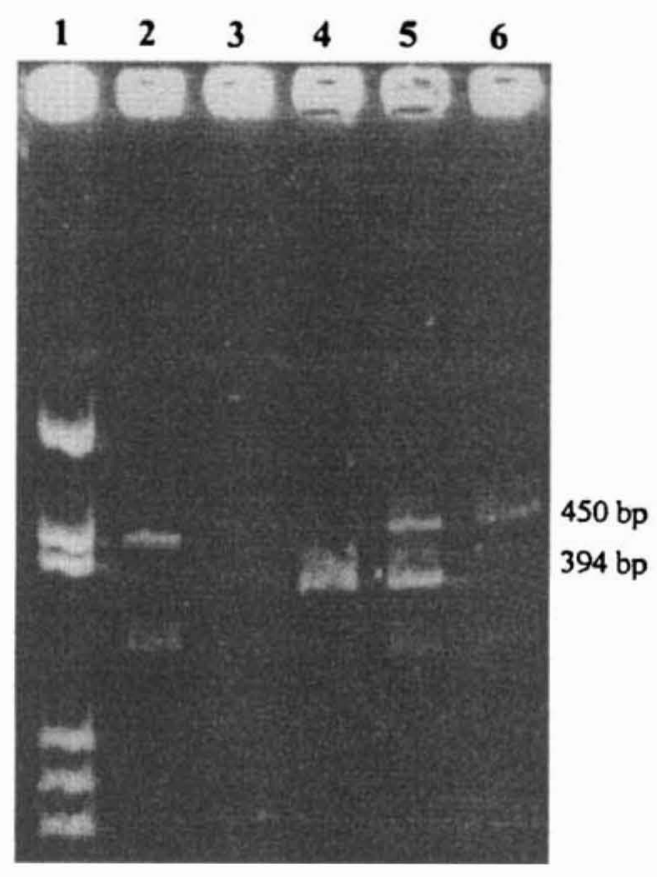

FIGURE 7. RT-PCR analysis of total RNA. Lane 1, size marker (pBluescript II KS digested with HaeIII); lane 2, RT-PCR product of obtained from 0.5 attomol internal standard RNA (450 bp); lane 3 control reaction with cellular RNA in which reverse transcriptase was omitted; lane 4, RT-PCR product obtained from cellular RNA before ribozyme treatment $(394 \mathrm{bp})$; lane 5, RT-PCR products obtained from RNA after treatment with the nonsense ribozyme; lane 6 , RT-PCR products obtained from RNA after treatment with the active ribozyme MRE763C.

diminishes availability of the ribozyme with a concomitant decrease in efficiency. Modifications usually lead to higher stablility against digestion by nucleases but are often accompanied by a decrease in catalytic efficiency.

The N-ras/luciferase reporter system used in our studies provides a very sensitive assay to detect ribozyme activity, since the expression of the luciferase reporter gene depends on an intact $\mathrm{N}$-ras sequence. This cell experiments revealed a reduction in luciferase activity of up to $55 \%$ in HeLa cells treated with MRE763C. A low but detectable antisense effect was also observed since incubation of HeLa cells expressing mutant $\mathrm{N}$ ras/luciferase fusion transcripts with the inactive forms of MRE763C or MRE764U resulted in a $20 \%$ reduction in luciferase activity. The cleavage activity of ribozyme 
MRE763C was restricted to mutated $\mathrm{N}$-ras sequences, as the luciferase activity in HeLa cells expressing a wild-type N-ras/Luciferase transcript was not reduced above the levels expected from an antisense effect.

Since the half-life of a ras/luciferase protein was not known, we estimated the cleavage efficiency at the RNA level by analysing directly the amount of mRNA molecules cleaved by the ribozyme MRE763C. For this type of analysis an internal RNA standard is required, since cleavage of the substrate may also occur during the RNA extraction protocol ${ }^{11}$. The amount of RT-PCR product obtained from the standard RNA can be estimated by densitometric evaluation of the ethidium bromide bands in the agarose gel and thus can be correlated to the amounts of input RNA in the reaction. A systematic analysis of the amounts of $\mathrm{N}$-ras/luciferase mRNA present in the HeLa clone C\#3 was conducted by mixing different amounts of total cellular RNA with a constant amount of standard RNA. At a standard concentration of 0.5 attomol $\left(3 \cdot 10^{5}\right.$ RNA molecules) equivalent RT-PCR signals from total cellular RNA and standard RNA were observed, suggesting that the amount of $\mathrm{N}$-ras/luciferase mRNA expressed in this cell clone was roughly $3 \cdot 10^{5}$ molecules. After treatment of the cells with ribozyme MRE763C, no visible RT-PCR product was observed (FIG. 7, lane 6). In vitro studies showed that these ribozymes were specific for the oncogenic form of $\mathrm{N}$-ras, since cleavage was observed only in a 849 nucleotides long transcript containing mutant but not wildtype $\mathrm{N}$ ras sequences.

Altogether the chemical approach compares well to the gene therapy strategy. in reducing the target mRNA.

ACKNOWLEDGEMENT We thank the Stiftung Stipendien-Fonds des Verbandes der Chemischen Industrie e.V. for financial support and F. Eckstein for hclpful discussions. C. Klebba is gratefully acknowledged for oligonucleotide synthesis. We also thank R. Häner for the generous gift of 2'-methoxyethoxy-modified ribonucleosides.

\section{REFERENCES}

1. Symons, R. H. Annu. Rev. Biochem. 1992 61, 641-671.

Bratty, J.; Chartrand, P.; Ferbeyre, G.; Cedergren, R. Biochim. Biophys. Acta. 1993 $1216,345-359$. 
2. Hutchins, C. J.; Rathjen, P. D.; Forster, A. C.; Symons R. H. Nucl. Acids Res. 1986 14, 3627-3640.

3. Hertel, K.J.; Pardi, A.; Uhlenbeck, O.C.; Koizumi, M.; Ohtsuka, E.; Uesugi, S.; Cedergren, R.; Eckstein, F.; Gerlach, W.L.; Hodgson, R.; Symons, R.H. Nucleic Acids Res. 1992 20, 3252.

4. Heidenreich, O.; Eckstein, F. J. Biol. Chem. 1992 267, 1904-1909.

Heidenreich, O.; Benseler, F.; Fahrenholz, A.; Eckstein, F. J. Biol. Chem. 1994 269, 2131-2138.

5. Edgington, S. M. Bio/Technology 1992 10, 152-154.

6. Bos, J. L. Mutat. Res. 1988 195, 255-271.

7. Portier, M.; Molès, J-P.; Mazars, G-R.; Jeanteur, P.; Bataille, R.; Klein, B.; Theillet, C. Oncogene 1992 7, 2539-2543.

8. Scherr, M.; Grez, M.; Ganser; A.; Engels, J. W. J. of Biol. Chem. 1997 272, 1430414313.

9. Scherr, M.; Klebba, C.; Häner, R.; Ganser, A.; Engels, J. W. Bioorg. \& Medicinal Chem. Lett 1997 7,1791-1796.

10. Reif, B.; Wittmann, V.; Schwalbe, H.; Griesinger, C.; Wörner, K.; Jahn-Hofmann, K.; Engels, J.W.; Bermel, W. Helvetica Chimica Acta 1997 80, in press.

11. Heidenreich, O.; Xiao, X.; Nerenberg, M. Antisense \& Nucleic Acid Drug Dev. 1996 6, 141-144.

Beck, J.; Nassal, M. Nucleic Acids Res. 1995 23, 4954-4962. 